\title{
Fullerenes and other carbon forms: studies by STM and cognate techniques
}

\author{
C.N.R. Rao *, Hemantkumar N. Aiyer, Ram Seshadri, A. Govindaraj \\ Solid State and Structural Chemistry Unit and CSIR Centre of Excellence in Chemistry, Indian Institute of Science, Bangalore 560 012, India
}

\begin{abstract}
Solid-state properties of fullerenes $\mathrm{C}_{60}$ and $\mathrm{C}_{70}$ with particular reference to orientational ordering, structural features and photopolymerization of the films, ferromagnetism in $\mathrm{C}_{60}$-TDAE and interaction of fullerene surfaces with metal clusters are discussed. Electronic properties of nanotubes as well as features of metal-filled hyperfullerenes are presented. The need to study other interesting forms of carbon such as diamond-graphite hybrids is indicated.
\end{abstract}

Keywords: Fullerene; Carbon; Scanning tunnelling microscopy; Nanostructures

\section{Introduction}

Fullerenes and other new carbon forms such as nanotubes and onions have become active areas of research in the last four years [1]. All these forms of carbon comprise six-and five-membered rings, the latter being essential for the formation of cage structures with no dangling bonds. There are many interesting solid-state properties of fullerenes. In this presentation, we shall briefly discuss some scanning tunneling microscopy (STM) results of $\mathrm{C}_{60}$ and $\mathrm{C}_{70}$ films, interaction of $\mathrm{C}_{60}$ and $\mathrm{C}_{70}$ surfaces with transition metal clusters as well as phase transitions and related aspects of the bulk fullerenes. Another aspect of interest to us is the photopolymerization of films of $\mathrm{C}_{60}$ and $\mathrm{C}_{70}$, nanotubes, especially their electrical properties, and some new results obtained on carbon onions. We shall then discuss other possible carbon forms, diamond-graphite hybrids in particular.

\section{STM studies of films}

Scanning tunneling microscopy has, from the very beginning, proved to be a very powerful probe of the fullerenes $[2,3]$. Thus, considerable information has been obtained in both the resolution of molecular structure as well as the $2 \mathrm{D}$ packing of $\mathrm{C}_{60}$ from studies of solid films. We have investigated $C_{60}$ and $C_{70}$ films and their mixtures deposited on solid

\footnotetext{
* Corresponding author.
}

substrates, with particular reference to orientational disorder [4,5]. Films of $C_{70}$ on single-crystal metal and oriented graphite surfaces reveal interesting features (Fig. 1). The disorder of the $\mathrm{C}_{70}$ molecules can be directly observed since the molecule has a long axis. This is not possible in $\mathrm{C}_{60}$, whose high symmetry precludes the orientation from being observed. Histograms of the distribution of projected angle $\phi$ that each molecule makes with respect to its neighbors can be constructed in order to characterize the disorder. The distributions are quite different on different substrates and are related to possible modes of registry between the fullerene lattice and the substrate lattice. Solid solutions of $\mathrm{C}_{60}$ and $\mathrm{C}_{70}$ on HOPG also display interesting orientational features [5] as shown in Fig. 1(c).

\section{Photopolymerization of fullerene films}

When $\mathrm{C}_{70}$ films on a HOPG substrate are exposed to UV radiation, the STM image changes considerably (Fig. 2). The intramolecular features become easily resolved, indicating that molecular motion is frozen. The other feature of note is that the STM images show a lattice expansion of $\sim 10 \%$ on polymerization. The observations can be explained by considering $2+2$ cyclization reactions between $6-6$ bonds in the end-caps of the neighboring $\mathrm{C}_{70}$ molecules. This symmetryallowed reaction results in the formation of chains of $C_{70}$ molecules which freezes molecular motion. X-ray diffraction (XRD) studies show that whereas the $\mathrm{C}_{70}$ lattice expands on 

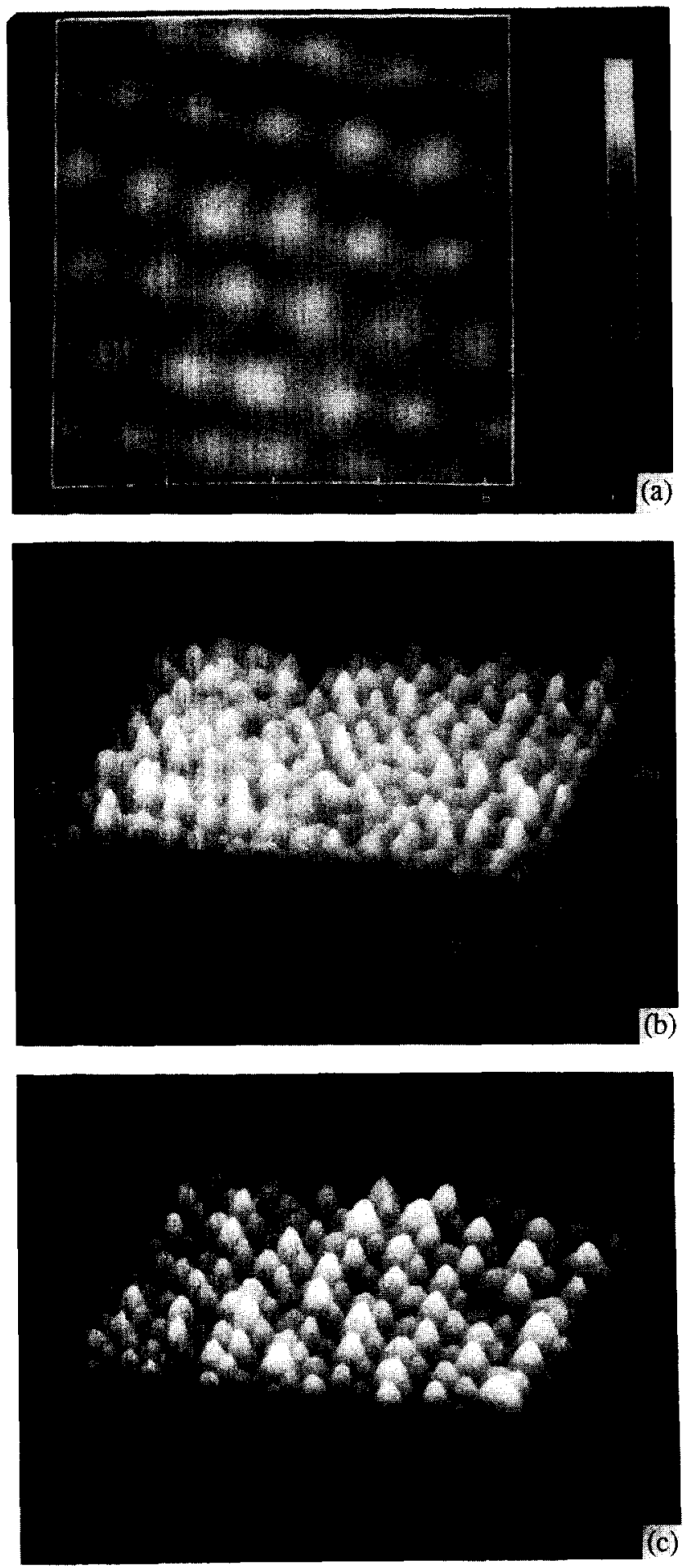

Fig. 1. STM images of $\mathrm{C}_{70}$ on (a) HOPG and (b) $\mathrm{Ag}(110)$ surfaces. The projected orientations of the molecules and the extent of orientational disorder is seen to depend on the substrate. (c) STM image of a mixture of $\mathrm{C}_{\mathrm{cti}}$ and $\mathrm{C}_{70}$ on a HOPG substrate. The initial mole ratios (before subliming) were $20: 80$.

photopolymerization, the $\mathrm{C}_{60}$ lattice contracts (by $\sim 12 \%$ ). This observation has some implications in understanding the pressure induced amorphization of $\mathrm{C}_{60}$ and $\mathrm{C}_{70}$ which is discussed later on in this article.
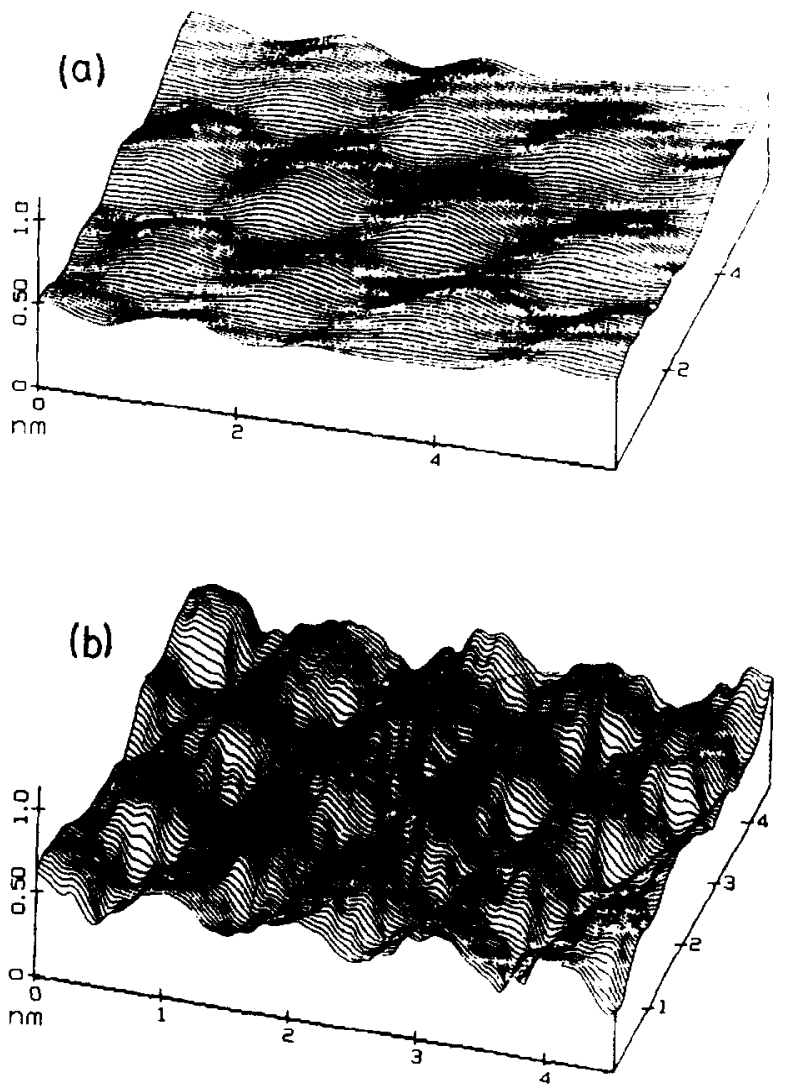

(c)

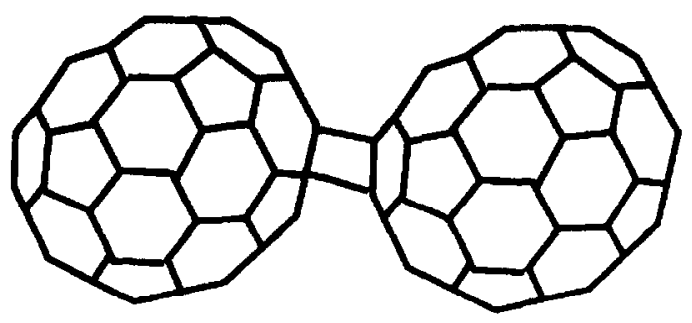

Fig. 2. (a) STM images of $\mathrm{C}_{70}$ on HOPG. (b) Image after exposure to a UV lamp. (c) A schematic diagram of the $2+2$ addition taking place between 6-6 bonds at the end caps of two $C_{70}$ molecules.

\section{Phase transitions of $\mathrm{C}_{610}$ and $\mathrm{C}_{70}$}

The structure and phase transitions associated with orientational ordcring and the formation of orientational glasses are fairly well understood in solid $\mathrm{C}_{60}[6,7]$. The situation with $\mathrm{C}_{70}$ is more complex. Vaughan et al. [8] found the high terperature, fully disordered fcc phase to convert to phases of lower symmetry on cooling, showing two transitions by differential scanning calorimetry at 337 and $276 \mathrm{~K}$. MD simulations [9] suggest that the free-rotor fcc phase goes to a partially ordered phase with trigonal symmetry and then on to a monoclinic phase. By following the IR [10] and Raman [11] modes in thin films, we were able to detect changes in the spectra around $340 \mathrm{~K}$ and $280 \mathrm{~K}$ (Fig. 3). High-pressure resistance measurements [12] however suggest that there may be as many as three phase transitions associated with 

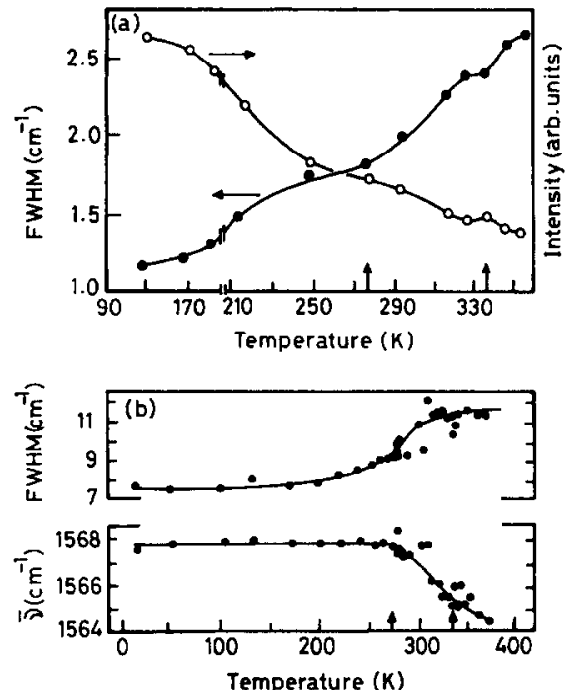

Fig. 3. Representative (a) IR and (b) Raman modes of $C_{70}$ films across the orientational ordering transitions. The temperatures corresponding to the transitions are indicated.

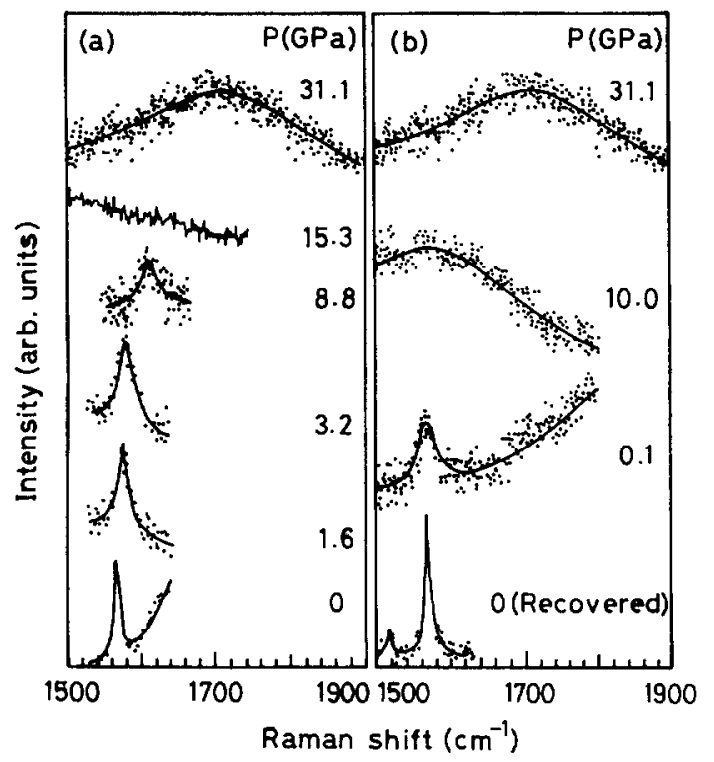

Fig. 4. Raman spectra of $C_{70}$ under (a) increasing pressure and (b) decreasing pressure showing the formation of an amorphous phase at high pressures and the reversibility of the process.

orientational ordering in solid $\mathrm{C}_{70}$; this is also supported by calorimetric measurements [13].

Raman studies of $\mathrm{C}_{70}$ under pressure seem to indicate that it forms an amorphous phase with a signal essentially due to $\mathrm{sp}^{2}$ carbon atoms at pressures exceeding $12 \mathrm{GPa}$ [14] (Fig. 4). This signal persists till at least $30 \mathrm{GPa}$. Decreasing the pressure back to ambient results in the original spectrum being recovered showing the amorphization to be reversible. In $\mathrm{C}_{60}$, however, the amorphization is irreversible. The amorphous phase formed above $22 \mathrm{GPa}$ has neighboring $\mathrm{C}_{60}$ units bonding with each other. This phase is retaincd cven on lowering the pressure $[15,16]$. The fact that $C_{60}$ is more compressible than $C_{70}[17,18]$ and also that the lattice contracts on photopolymerizing $\mathrm{C}_{60}$ suggests why pressure would favor photopolymerization in $\mathrm{C}_{60}$. This provides a clue as to why amorphization occurs and is irreversible in $\mathrm{C}_{60}$.

\section{Interaction of fullerene films with $\mathrm{Ni}$ and $\mathrm{Cr}$ clusters}

$\mathrm{C}_{60}$ and $\mathrm{C}_{70}$ have high electron affinity and can be intercalated/electron doped with alkali and alkaline-earth metals to form salts [19]. The electron doping by alkali metals in $\mathrm{C}_{60}$ results in the $\mathrm{C}_{60} \mathrm{t}_{1 \mathrm{u}}$-derived conduction band being filled with electrons, forming successively the metal (corresponding to $A_{3} \mathrm{C}_{60}$ ) and the band insulator (corresponding to $A_{6} \mathrm{C}_{60}$ ). These electron doping studies have been extensively followed by electron spectroscopic techniques [20] which, with increasing doping, clearly show the filling up of the density of states due to $C_{60}$ levels near the Fermi energy. Concomitantly, the entire spectra shift to lower energy due to Fermi level pinning. Our interest concerns the interaction of fullerene films with metal clusters, particularly of the transition metals $[21,22]$. $\mathrm{C}_{60}$ films on polycrystalline gold substrates were grown by resistive evaporation of the fullerenes from quartz boats in the high-vacuum preparation chamber of the spectrometer. Clusters of $\mathrm{Ni}$ and $\mathrm{Cr}$ metals were further deposited on the fullerene films by evaporation from a tungsten filament. $C$ is core level spectra of $\mathrm{C}_{60}$ show that with increasing $\mathrm{Ni}$ deposition, the binding energy shifts to lower energies suggesting charge transfer from $\mathrm{Ni}$ to the fullerene. Accordingly, the Ni $2 p$ spectra show a larger positive binding energy shift (Fig. 5). The same effect is seen when $\mathrm{Cr}$ is deposited on the fullerene films. Both $\mathrm{Ni}$ and $\mathrm{Cr}$ seem to transfer charge to $\mathrm{C}_{70}$ films also. To ensure that the binding energy shift is not due to electrical grounding of the fullerene film, we have performed the same expcriment with graphitc as the substrate for metal deposition. No change in the graphite $\mathrm{C} 1 \mathrm{~s}$ binding energy is seen. Cu does not seem to transfer charge to the fullerenes, suggesting that the metal-fullerene interaction in specific and possibly involved $\mathrm{d} \pi-\mathrm{p} \pi$ charge transfer.

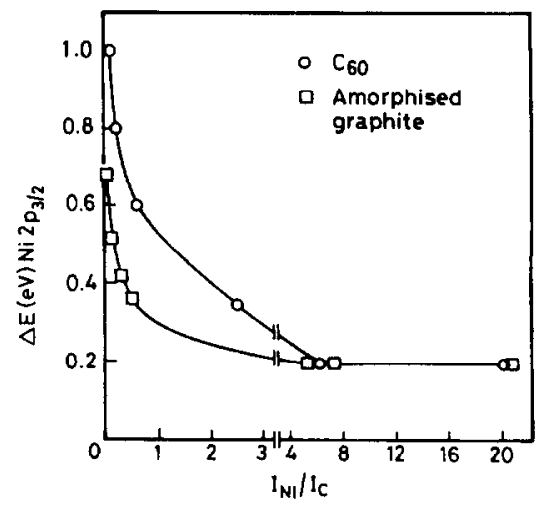

Fig. 5. Change in the $\mathrm{Ni} 2 \mathrm{p}_{3 / 2}$ binding energy of $\mathrm{Ni}$ on $\mathrm{C}_{60}$ and on graphite ( for comparison) with respect to the clean surface, as a function of increasing $\mathrm{Ni}$ deposition. The extra shift shown by $\mathrm{Ni}$ on $\mathrm{C}_{60}$ is inferred to result from charge transfer from $\mathrm{Ni}$ to $\mathrm{C}_{60}$. 
I
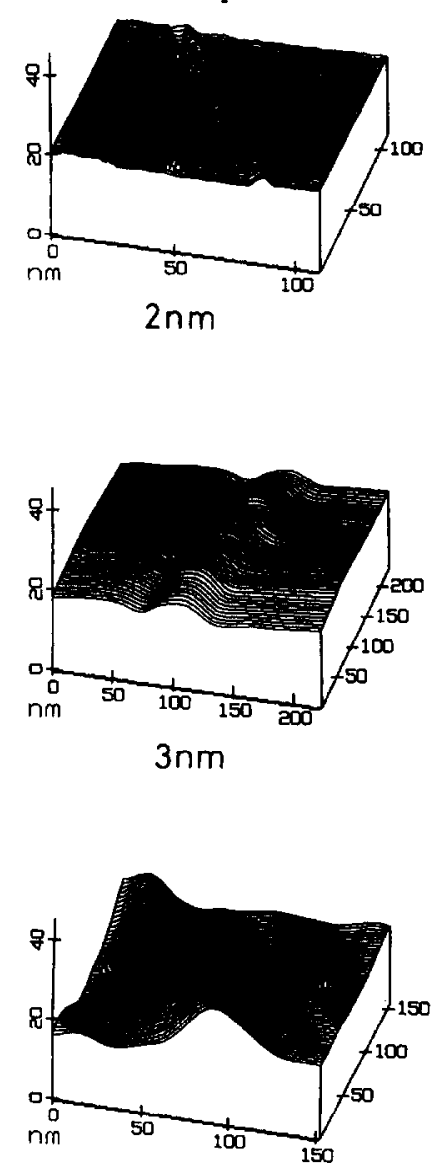

$9.7 \mathrm{~nm}$
II
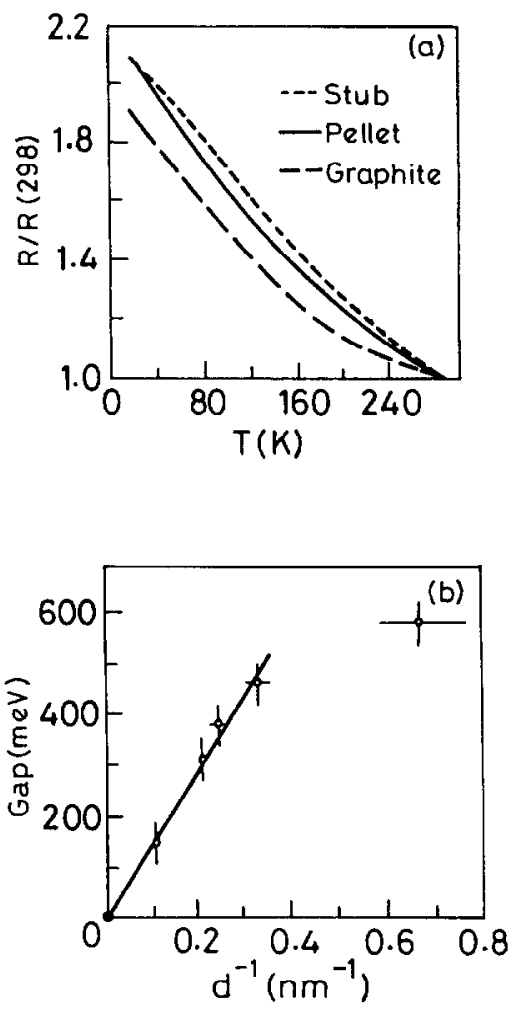

Fig. 6. (I) STM line profiles of carbon nanotubes of different diameters on HOPG. The diameters are indicated. (II) (a) Temperature dependence of the scaled electrical resistances of clean carbon nanotubes and the cathodic stub. The resistance of a graphitic pellet is shown for comparison. (b) Plot of the conductance gap obtained from STM studies vs. the inverse diameter, $d^{-1}$.

\section{Ferromagnetism in $\mathrm{C}_{60}$-TDAE}

The discovery of soft ferromagnetism below $16 \mathrm{~K}$ in the organic sait of $\mathrm{C}_{60}$ with the donor molecule tetrakisdimethylamino ethylene was an important landmark in this field [23]. We have studied this system by electron spin resonance [24] and Raman spectroscopy [25]. The former confirms the occurrence of ferromagnetism and has allowed us to propose that the system is a spin $-1 / 2$ Heisenberg ferromagnet with mostly $1 \mathrm{D}$ interactions. The ferromagnetism arises out of a McConnel-type mechanism for ferromagnetic organic metals, involving the stabilization of a ground state triplet via configuration interaction. Titrations of the Raman phonon frequencies confirm the single electron doping from TDAE to $\mathrm{C}_{60}$.

\section{Carbon nanotubes}

Carbon nanotubes, discovered by lijima [26], are exciting additions to the field of carbon structures. Extensive studies on the preparation, structure and properties of carbon nanotubes and nanocapsules have been performed in this lab [27].
In this section, we review the electronic properties of carbon nanotubes as probed by electrical transport and thermopower studies and by scanning tunneling microscopy/spectroscopy.

Considering the novelty of this material and the plethora of theoretical results regarding their electronic properties, we considered it of interest to examine their electron transport properties [28]. Electrical resistance measurements on sam-
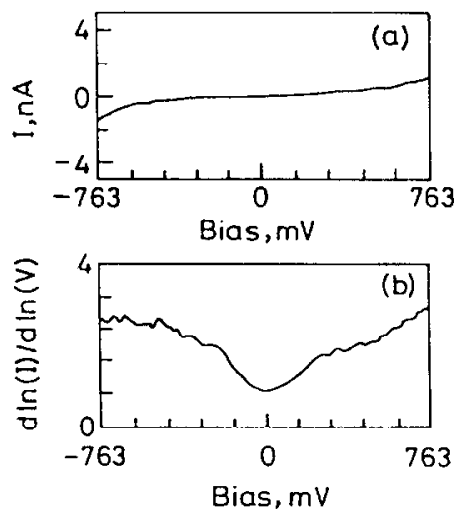

Fig. 7. (a) Typical $I-V$ curve; and (b) the corresponding normalized tunneling conductance $[\mathrm{d} \ln (I) / \mathrm{dln}(V)-V]$ spectrum of a $1.5 \mathrm{~nm}$ diameter nanotube. 


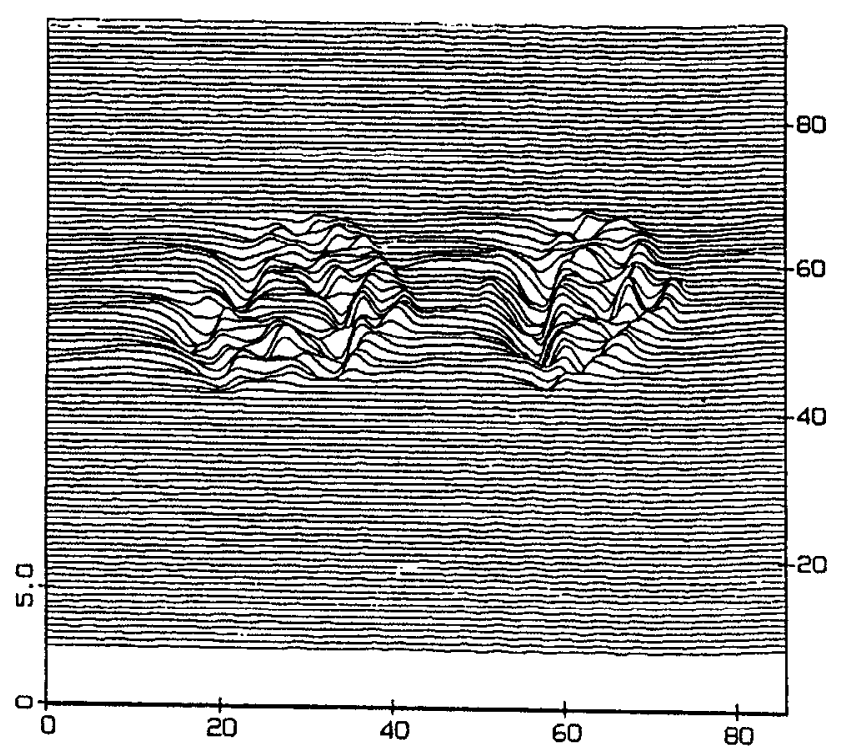

Fig. 8. STM lineplot of carhon onions deposited on a HOPG substrate.

ples of carbon nanotubes which were cleaned of extraneous graphitic particles by burning, suggest that bulk nanotubes behave much like polycrystalline graphite in terms of the magnitudes and temperature dependence of the electrical resistivity. The behaviour is that of a small bandgap semiconductor. Thermopower studies suggest that nanotubes resemble samples of incompletely graphitized carbons, with small phonon drag contributions to the thermopower. We have been able to study the $I-V$ characteristics of individual nanotubes deposited on a HOPG substrate using a scanning tunneling microscope (Fig. 6). A typical $I-V$ curve and the corresponding normalized tunneling conductance (dln $(I) /$ dln $(V)-V)$ spectrum of a nanotube showing a tunneling conductance gap is shown in Fig. 7. The smaller nanotubes show a bandgap in the conductivity which scales inversely as their diameter. This suggests the role of finite size effects in the electronic properties of carbon nanotubes.

\section{Carbon onions}

The discovery of the curling and closure of small graphitic particles under intense electron beam irradiation by Ugarte [29] has given rise to a new carbon form, namely carbon onions. STM reveals nanocapsules formed along with nanotubes to be polyhedral. Fig. 8 shows a STM lineplot of carbon nanocapsules/onions deposited on a HOPG substrate. By using graphite anodes which have been filled with transition metals, we are able to obtain, after arcing in $\mathrm{He}$, nanometric metal particles of iron, cobalt and nickel in the soot (particles in the $2-15 \mathrm{~nm}$ range) as well as in the stub formed on the cathode (larger particles) [30]. Mössbauer spectroscopy confirms that some of the smaller iron particles in the soot are superparamagnetic. What is of interest is that even these very small (sub-5 $\mathrm{nm}$ ) iron particles are extremely resistant to oxidation due to a protective graphitic sheathing.

\section{Other carbon forms including diamond-graphite hybrids}

The discovery of fullerenes and nanotubes has emphasized the importance of exploring the possibility of novel carbon

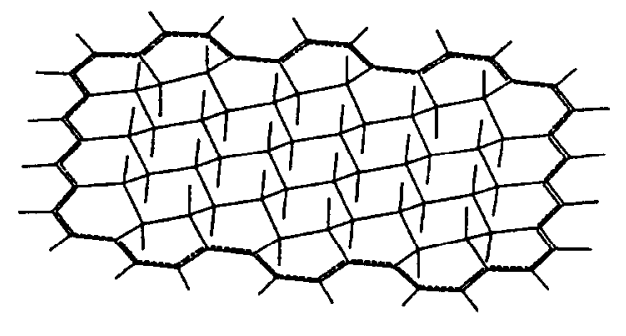

a

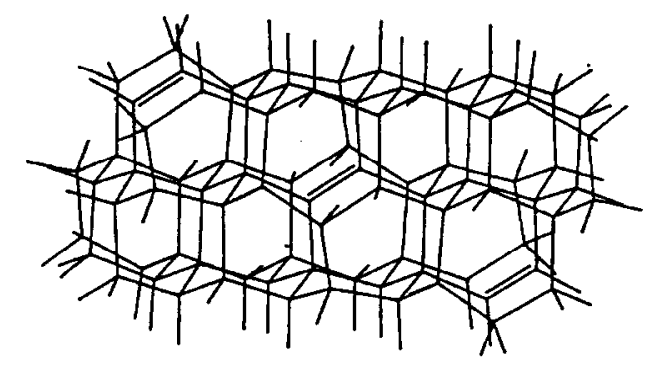

b

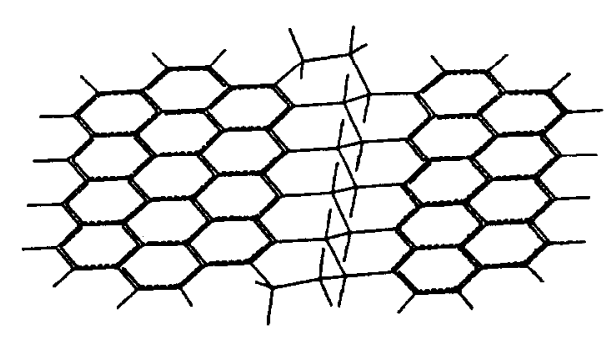

$a^{\prime}$

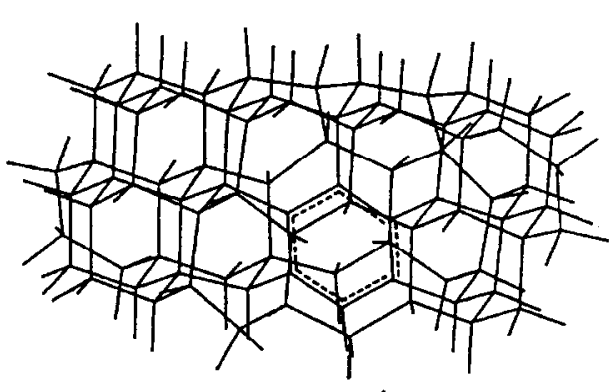

b'

Fig. 9. Molecular mechanics minimized structure of diamond-graphite hybrid: (a) and ( $a^{\prime}$ ) are portions of a graphite lattice with finite diamond-like units. (b) A portion of a diamond lattice with three isolated double bonds. ( $b^{\prime}$ ) The three double bonds in (b) have fused to form a benzene ring. 
forms. New carbon forms formed by five-, six- and sevenmembered rings, the latter providing negative curvature unlike the positive curvature provided by five-membered rings, are worth pursuing [31]. In the area of amorphous carbons, including diamond-like carbons, many questions regarding structure and electronic properties remain unanswered. In this light, we have employed molecular modelling tools to study possible hybrid structures that can be formed using $\mathrm{sp}^{2}$ and $\mathrm{sp}^{3}$ carbons (diamond-graphite hybrids) [32] . In order to model such structures, it is necessary to cap dangling bonds with hydrogen atoms. Thus these structures are actually molecular rather than extended. Nevertheless, insight on how $\mathrm{sp}^{2}$ atoms in a largely $\mathrm{sp}^{3}$ framework (or the converse) distribute can be obtained. Fig. 9 shows an example of one such structure with a $\mathrm{sp}^{3}$ carbon atom in an otherwise $\mathrm{sp}^{2}$ network as well as structures with double bonds in a diamond lattice.

\section{Acknowledgements}

This work is supported by the Jawaharlal Nehru Centre for Advanced Scientific Research.

\section{References}

[1] MRS Bull, XIX (1994).

[2] J. H. Weaver and D.M. Poirier, in H. Ehrenreich and F. Spaepen (eds.), Solid State Phys., 48 (1994) 1.

[3] X.D. Wang, T. Hashizume and T. Sakurai, Mod. Phys. Lett., 8 (1994) 1397.

[4] H.N. Aiyer, A. Govindaraj and C.N.R. Rao, Bull. Mater. Sci., 17 (1994) 563.

[5] H.N. Aiyer, A. Govindaraj and C.N.R. Rao, Phil. Mag. Lett., 72 (1995) 185.

[6] P.A. Heiney, J.E. Fischer, A.R. McGhie, W.J. Romanow, A.M. Denenstein, J.P. McCauley, Jr., and A.B. Smith III, Phys. Rev. Lett. 66 (1991) 2911.

[7] W.I.F. David, R.M. Ibberson, J.C. Matthewman, K. Prassides, T.J.S. Dennis, J.P. Hare, H.W. Kroto, R. Taylor and D.R.M. Walton, Nature. 353 (1991) 147.
[8] G.B.M. Vaughan, P.A. Heiney, J.E. Fischer, D.E. Luzzi, D.A.RickettsFoot, A.R. McGhie, Y.-W. Hui, A.L. Smith. D.E. Cox. W.J. Romanow, B.H. Allen, N. Coustel, J.P. McCauley, Jr., and A.B. Smith III, Science, 254 (1991) 1350.

[9] M. Sprik, A. Cheng and M.L. Klein, Phys. Rev. Lett. 69 (1992) 1660.

[10] V. Varma, R. Seshadri, A. Govindaraj, A.K. Sood and C.N.R. Rao, Chem. Phys. Lett., 203 (1993) 545.

[11] N. Chandrabhas, K. Jayaraman, D. V.S. Muthu. A.K. Sood, R. Seshadri and C.N.R. Rao, Phys. Rev., B47 (1993) 10963.

[12] S.K. Ramasesha, A.K. Singh, R. Seshadri. A.K. Sood and C.N.R. Rao, Chem. Phys. Lett. 220 ( 1994) 203.

[13] J. Sworakowski, K. Palewska and M. Bertault. Chem. Phys. Lett. 220 (1994) 197

[14] N. Chandrabhas, A.K. Sood, D.V.S. Muthu, C.S. Sundar, A. Bharathi, Y. Hariharan and C.N.R. Rao, Phys. Rev: lett., 73 (1994) 3411.

[15] F. Moshary, N.H. Chen, I.H. Silvera, C.A. Brown, H.C. Dorn, M.S. deVries and D.S. Bethune, Phys. Rev. Leth. 69 (1992) 466.

[16] C.S. Yoo and W.J. Nellis, Chem. Phys. Lett., 198 (1992) 379.

[17] S.J. Duclos, K. Brister, R.C. Haddon, A.R. Konta and F.A. Thiel, Nature, 351 (1991) 380.

[18] C. Christides, I.M. Thomas, T.J.S. Dennis and K. Prassides, Europhys. Lett., 22 (1993) 545.

[19] R.C. Haddon, Acc. Chem. Res. 25 (1992) 127.

[20] J.H. Weaver, J. Phys. Chem. Solids, 53 (1992) 1433.

[21] V. Vijayakrishnan, A.K. Santra, R. Seshadri, R. Nagarajan, T. Pradeep and C.N.R. Rao, Indian J. Chem., 31A\&B (1992) F22.

[22] A.K. Santra, R. Seshadri, A. Govindaraj, V. Vijayakrishnan and C.N.R. Rao, Solid State Commun. 85 (1993) 77.

[23] P.M. Allemand, K.C. Khemani, A. Koch, F. Wudl, K. Holczer, S Donovan, G. Gruner and J.D. Thompson, Science. 253 (1991) 301.

[24] R. Seshadri, A. Rastogi, S.V. Bhat, S. Ramasesha and C.N.R. Rao, Solid State Commun. 85 (1993) 971.

[25] D.V.S. Muthu, M.N. Shashikala, A.K. Sood, R. Seshadri and C.N.R. Rao, Chem. Phys. Lett., 217 (1994) 146.

[26] S. lijima, Nature, 354 (1991) 56.

[27] R. Seshadri, R. Sen, H.N. Aiyer, A. Govindaraj, G.N. Subbanna, A.R. Raju and C.N.R. Rau, Curr. Sci. (India). 66 (1994) 839.

[28] R. Seshadri, H.N. Aiyer, A. Govindaraj and C.N.R. Rao, Solid State Commun., 91 (1994) 195.

[29] D. Ugarte, Nature, 359 (1992) 707.

[30] R. Seshadri, R. Sen, K.R. Kannan, G.N. Subbanna and C.N.R. Rao. Chem. Phys. Lett. 231 (1994) 308.

[31] H.W. Kroto, J.P. Hare, A. Sarkar, K. Hsu, M. Terrones and R. Abeysinghe. MRS Bulletin, XIX (1994) 51

[32] R. Sen, R. Sumathy and C.N.R. Rao, J. Mater. Res.. 10 (1995) 2531. 